\title{
Optimization of culture conditions for secondary mycelial growth of wild macrofungi from selected areas in Central Luzon, Philippines
}

\author{
Kalaw $\mathrm{SP}^{1,2}$, Alfonso $\mathrm{DO}^{2}$, Dulay $\mathrm{RMR}^{1,2}$, De Leon $\mathrm{AM}^{1}$, Undan $\mathrm{JQ}^{2}$, Undan $\mathrm{JR}^{1}$ \\ and Reyes, RG ${ }^{1,2}$
}

${ }^{I}$ Department of Biological Sciences, College of and Sciences, Central Luzon State University, Science City of Muñoz, Nueva Ecija, Philippines

${ }^{2}$ Center for Tropical Mushroom Research and Development, Central Luzon State University, Science City of Muñoz, Nueva Ecija, Philippines

Kalaw SP, Alfonso DO, Dulay RMR, De Leon AM, Undan JQ, Undan JR, Reyes RG 2016 Optimization of culture conditions for secondary mycelial growth of wild edible mushrooms from selected areas in Central Luzon, Philippines. Current Research in Environmental \& Applied Mycology 6(4), 277-287, Doi 10.5943/cream/6/4/5

\begin{abstract}
This work highlighted the optimum culture conditions for secondary mycelia of selected Philippine wild macrofungi. The growth of different macrofungal species were evaluated on various indigenous culture media namely: coconut water gulaman, corn grit decoction gulaman, rice bran decoction gulaman, potato sucrose gulaman and potato dextrose agar (control). The effect of different physical conditions such as $\mathrm{pH}$, illumination and temperature was also investigated. The daily mycelia diameter, mycelial density and incubation period were used in determining the optimum growth conditions.

Among the indigenous culture media evaluated, coconut water gulaman significantly recorded the largest mycelia growth diameter in ten mushroom species/strains (mostly lignolytic) while potato sucrose gulaman favored the growth of two strains of $V$. volvacea. No significant difference in mycelial diameter of $C$. cinerea Sto Domingo strain on different indigenous culture media was recorded In terms of the $\mathrm{pH}$ of the media, most of the evaluated mushrooms registered maximum mycelial growth and very thick to thick mycelial density in a medium having a $\mathrm{pH}$ ranging from 6.0 to 7.0. Moreover, illumination significantly influenced the mycelial growth of four mushroom species. Incubation in lighted condition favored the growth of $L$. sajor caju, and S. commune CLSU strain whereas dark condition showed maximum growth of G. lucidum strain B and L. tigrinus CLSU strain. G. lucidum strain A, L. tigrinus CLSU strain, G. lucidum strain B and C. cinerea Sto Domingo strain incubated at room temperature $\left(32 \pm 0.91^{\circ} \mathrm{C}\right)$ significantly exhibited wider mycelia diameter and shorter incubation period than those in air condition $\left(23 \pm 1.35^{\circ} \mathrm{C}\right)$. No mycelial growth was observed at $9^{\circ} \pm 0.0{ }^{\circ} \mathrm{C}$.
\end{abstract}

Key words - indigenous culture media - physical factors $-\mathrm{pH}$ - illumination - temperature

\section{Introduction}

The Philippines is blessed with rich mycological resources which are proliferating on different substrates and geographical locations across the archipelago (Reyes et al. 2013). Wild macrofungi are commonly found in different habitat such as grasslands, forests, mountains, agricultural lands and industrial sites growing on decaying logs of trees, soil, manure of domesticated animals such as water buffaloes, horses and cattle and decomposing leaves and rotting logs of trees during the onset and middle part of rainy season (Kalaw \& Albinto, 2014, Dulay et al, 2014, Bustillos et al. 2014, Dulay et 
al. 2015). In the Philippines, intensive studies on the nutraceutical and pharmacological attributes of wild plants have been conducted. However, aside from plants, wild macrofungi can also be explored as possible sources of biologically and physiologically active compounds for medicinal purposes. In the Philippines researches on the use of macrofungi as sources of bioactive compounds for the treatment of human diseases are limited. These mycological resources can be harnessed for culinary, nutraceutical and pharmacological purposes. In general, the fruiting bodies of mushrooms are rich in proteins, carbohydrates, fats, fibers, vitamins and minerals (Reyes et al. 2013, Dulay et al. 2014, Kalaw \& Albinto 2015, Eguchi et al. 2015. Bioactive compounds obtained from macrofungi such as ergosterol, polysaccharides and beta glucan exhibited pharmacological properties (Ragasa et al. 2016, Klaus et al. 2009, Elsayid et al. 2014). Several species of mushrooms exhibited antimicrobial, anti-inflammatory, antioxidant and radical scavenging activities (Akyuz et al. 2010, Puttaraju et al. 2006, Elsayid et al. 2014).

To maintain a ready supply of macrofungi cell lines and fruiting bodies for evaluation of their nutraceutical and pharmacological attributes, determination of the optimal conditions for mycelial growth is important. In our desire to develop production technology and later to isolate novel compounds from Philippine wild macrofungi, we evaluated the optimal growth conditions for mycelial growth of different species of macrofungi collected from selected areas in Central Luzon, Philippines.

\section{Materials \& Methods}

\section{Collection and isolation of mushroom samples}

Wild macrofungi namely: Ganoderma lucidum, Lentinus tigrinus, Volvariella volvacea, Coprinopsis cinerea, Schizophyllum commune, Pleurotus cystidiosus, Lentinus sajor caju and Auricularia polytrica were collected from different sites in Central Luzon. The collected fruiting bodies were brought to the laboratory. The secondary mycelia were rescued following the standard procedure in mushroom tissue culture (Reyes et al. 1998). Small tissue from the inner part of macrofungi was cut and aseptically inoculated into potato dextrose agar. The cultures were incubated at room temperature to allow mycelial growth. These served as stock culture and used as source of inocula for the assessment of secondary mycelial growth. Different mushroom species were sub-cultured in sterile potato dextrose agar and incubated at ambient room temperature $\left(32 \pm 0.91^{\circ} \mathrm{C}\right)$ for 7 days.

\section{Influence of indigenous culture media}

To evaluate the most appropriate culture media for efficient mycelial growth of different macrofungal species, four indigenous culture media were evaluated namely; potato sucrose (25\% potato cubes and $1 \%$ sucrose) gulaman (PSG), rice bran decoction (5\% rice bran) gulaman (RBG), coconut water (mature coconut water) gulaman $(\mathrm{CWG})$, and corn grit decoction (broth from 5\% yellow corn grit) (CGG). Commercial potato dextrose agar (Hi media) was used as the control. The $\mathrm{pH}$ of the media was adjusted to $\mathrm{pH} 6$, sterilized at $15 \mathrm{psi}, 121{ }^{\circ} \mathrm{C}$ for 20 minutes and dispensed in a sterile petri plates. A $10 \mathrm{~mm}$ mycelial disc from 7 day old mycelia of different macrofungi species was separately inoculated at the center of the medium. The inoculated plates were incubated at room temperature. Each set-up was replicated three times for each mushroom species. The diameter mycelial growth was measured using digital vernier caliper until the plates were completely ramified with mycelia. The mycelial density was determined qualitatively such as: very thick $(++++)$, thick $(+++)$, thin $(++)$ and very thin $(+)$. The incubation period is the number of days from inoculation to complete mycelial ramification.

\section{Evaluation of the Influence of Physical Factors}

\section{pH}

The most appropriate culture media for each species of macrofungi was used as medium in the evaluation of physical factors. The influence of $\mathrm{pH}$ was assessed by separately inoculating a $10 \mathrm{~mm}$ mycelial disc of different macrofungi species in the medium with varying $\mathrm{pH}$ levels $(6.0-8.0$ at 0.5 intervals). The $\mathrm{pH}$ of the medium was adjusted using $0.1 \mathrm{M} \mathrm{NaOH}$ or $0.1 \mathrm{M} \mathrm{HCl}$ and sterilized at 15 
psi, $121^{\circ} \mathrm{C}$ for 20 minutes. The plates were incubated at room temperature and the daily mycelial diameter, mycelial density and incubation period were determined.

\section{Illumination}

The influence of illumination on mycelial growth was determined by incubating the culture plates in lighted and dark conditions. In lighted condition, the plates were placed in a chamber with artificial light while in dark conditions the plates were covered with clean carbon paper. All the plates were incubated at room temperature. The daily mycelial diameter, mycelial density and incubation period were determined

\section{Temperature}

The most suitable temperature was determined using three temperature conditions: refrigerated $\left(9{ }^{\circ} \mathrm{C}\right)$, air conditioned $\left(23{ }^{\circ} \mathrm{C}\right)$ and room temperature $\left(32{ }^{\circ} \mathrm{C}\right)$. The plates containing the different macrofungi species were separately incubated in these conditions. The daily mycelial diameter, mycelial density and incubation period were determined.

\section{Statistical Analysis}

The experiments were laid out in randomized complete design. The data collected were analyzed using SAS version 9 program. Means were compared using least significant difference (lsd) at $5 \%$ level of significance.

\section{Results \& Discussion}

\section{Influence of indigenous culture media}

Culture media are important factor that can influence the mycelial growth because they provide the nutrients needed by the organisms (Kibar \& Peksen 2011). The luxuriance and the rate of mycelial growth depend on the nutrient content of the culture media. In the present study, four indigenous culture media namely: rice bran decoction gulaman (RBG), potato sucrose gulaman (PSG), coconut water gulaman (CWG) and corn grit gulaman (CGG) were evaluated. Potato dextrose agar (PDA), a commercial medium, served as the control. Table 1 shows the mycelial diameter, mycelial density and incubation period of different macrofungi species on various indigenous culture media. Significant differences in the mean mycelial diameter and incubation period were observed among the indigenous media used. Most of the macrofungi species registered widest mycelial diameter and shortest incubation period in coconut water gulaman. However, in case of the two strains of $V$. volvacea the largest colony diameter and shortest incubation period was observed in potato sucrose gulaman. No significant difference in mycelial diameter of $C$. cinerea Sto. Domingo strain in the different culture media was recorded. However, significant difference in incubation period was noted. These results indicate that the mycelial growth on different indigenous culture media evaluated varies according to macrofungi species. This observation confirms the finding of Kibar and Peksen (2011) who disclosed that the effect of culture media on mycelial growth differed according to the mushroom species. The significant variation in the mycelial growth response could be due to the difference in the nutrient composition of the indigenous culture media evaluated. Different macrofungi species may have different nutritional requirement for mycelial growth. The luxuriant growth of mycelia in coconut water gulaman can be attributed to the nutritional content of coconut water. Coconut water contains sugars, inorganic ions, vitamins, minerals, amino acids, enzymes, phytohormones, and trace elements (Fife 2008, Yong et al. 2009). The result of this study confirm previous reports that coconut water gulaman is an ideal medium for the mycelial growth of macrofungi such as L. tigrinus (Dulay et al. 2012) and Lentinus squarrosulus and Polyporus grammocephalus (De Leon et al. 2013). On the other hand, theluxuriant growth of $V$. volvacea on potato sucrose gulaman could be due to the nutrient content of potato such as fructose, sucrose, amylase protein, vitamins such as thiamine, niacin, folic acid and minerals (Borlingame et al. 2009). 
Table 1 Mycelial diameter, mycelial density and incubation period of different mushroom species in different indigenous culture media.

\begin{tabular}{|c|c|c|c|c|c|c|}
\hline \multirow[b]{2}{*}{ Mushroom Species } & \multirow{2}{*}{$\begin{array}{l}\text { Culture } \\
\text { media }\end{array}$} & \multicolumn{3}{|c|}{$\begin{array}{c}\text { Secondary Mycelial Growth } \\
\text { Diameter }(\mathrm{mm})\end{array}$} & \multirow[t]{2}{*}{$\begin{array}{l}\text { Mycelial } \\
\text { Density }\end{array}$} & \multirow[t]{2}{*}{$\begin{array}{c}\text { Incubation } \\
\text { Period (days) }\end{array}$} \\
\hline & & Day 1 & Day 2 & Day 3 & & \\
\hline \multirow[t]{5}{*}{ G. lucidum strain A } & PDA & $15.03^{b}$ & $34.61^{b}$ & $57.49^{\mathrm{a}}$ & ++++ & $6.00^{\mathrm{a}}$ \\
\hline & RBG & $13.97^{\mathrm{c}}$ & $28.99^{\mathrm{d}}$ & $34.08^{\mathrm{b}}$ & ++ & $6.67^{\mathrm{ab}}$ \\
\hline & PSG & $13.94^{\mathrm{c}}$ & $26.88^{\mathrm{e}}$ & $44.20^{\mathrm{ab}}$ & ++ & $6.67^{\mathrm{ab}}$ \\
\hline & CWG & $16.82^{\mathrm{a}}$ & $38.79^{\mathrm{a}}$ & $57.99^{\mathrm{a}}$ & +++ & $5.67^{\mathrm{b}}$ \\
\hline & CGG & $14.17^{\mathrm{bc}}$ & $32.16^{\mathrm{c}}$ & $50.58^{\mathrm{ab}}$ & + & $6.67^{\mathrm{ab}}$ \\
\hline \multirow[t]{5}{*}{ G. lucidum strain B } & PDA & $17.39^{\mathrm{b}}$ & $38.69^{\mathrm{abc}}$ & $63.12^{\mathrm{ab}}$ & ++++ & $6.67^{\mathrm{b}}$ \\
\hline & $\mathrm{RBG}$ & $17.34^{\mathrm{b}}$ & $39.54^{\mathrm{ab}}$ & $57.01^{\text {bc }}$ & ++ & $6.67^{\mathrm{b}}$ \\
\hline & PSG & $16.01^{\mathrm{b}}$ & $35.33^{b c}$ & $51.46^{\mathrm{bc}}$ & +++ & $5.67^{\mathrm{a}}$ \\
\hline & CWG & $20.85^{\mathrm{a}}$ & $43.44^{\mathrm{a}}$ & $66.91^{\mathrm{a}}$ & +++ & $5.33^{\mathrm{a}}$ \\
\hline & CGG & $16.50^{\mathrm{b}}$ & $32.65^{\mathrm{c}}$ & $45.79^{\mathrm{d}}$ & + & $6.67^{\mathrm{b}}$ \\
\hline L. tigrinus & PDA & $13.75^{\mathrm{a}}$ & $26.78^{\mathrm{a}}$ & $49.70^{\mathrm{a}}$ & ++++ & $6.00^{\mathrm{b}}$ \\
\hline \multirow[t]{4}{*}{ CLSU strain A } & RBG & $14.40^{\mathrm{a}}$ & $26.00^{\mathrm{a}}$ & $42.25^{\mathrm{b}}$ & ++ & $7.33^{\mathrm{ab}}$ \\
\hline & PSG & $11.74^{\mathrm{b}}$ & $20.54^{\mathrm{b}}$ & $33.93^{c}$ & ++ & $9.67^{\mathrm{a}}$ \\
\hline & CWG & $12.49^{\mathrm{c}}$ & $26.49^{\mathrm{a}}$ & $48.78^{\mathrm{a} b}$ & +++ & $6.33^{\mathrm{ab}}$ \\
\hline & CGG & $11.40^{\mathrm{d}}$ & $18.40^{\mathrm{b}}$ & $34.10^{c}$ & + & $8.67^{\mathrm{ab}}$ \\
\hline L. tigrinus & PDA & $11.91^{\mathrm{a}}$ & $27.82^{\mathrm{a}}$ & $51.13^{\mathrm{a}}$ & ++++ & $6.67^{\mathrm{b}}$ \\
\hline \multirow[t]{4}{*}{ CLSU strain B } & RBG & $10.58^{\mathrm{ab}}$ & $19.01^{\mathrm{b}}$ & $29.63^{c}$ & ++ & $9.33^{\mathrm{a}}$ \\
\hline & PSG & $11.09^{\mathrm{ab}}$ & $25.3^{\mathrm{a}}$ & $41.96^{\mathrm{b}}$ & ++ & $9.33^{\mathrm{a}}$ \\
\hline & CWG & $11.83^{\mathrm{a}}$ & $27.22^{\mathrm{a}}$ & $50.43^{\mathrm{a}}$ & +++ & $6.67^{\mathrm{b}}$ \\
\hline & RBG & $10.18^{\mathrm{b}}$ & $18.8^{\mathrm{b}}$ & $33.57^{\mathrm{c}}$ & + & $7.33^{\mathrm{ab}}$ \\
\hline V. volvacea & PDA & $15.86^{\mathrm{ab}}$ & $38.44^{\mathrm{b}}$ & $64.91^{\mathrm{b}}$ & ++++ & $5.00^{\mathrm{b}}$ \\
\hline \multirow[t]{4}{*}{ Rang-ayan strain } & RBG & $14.70^{\mathrm{ab}}$ & $35.49^{\mathrm{b}}$ & $53.79^{c}$ & +++ & $5.00^{\mathrm{b}}$ \\
\hline & PSG & $17.39^{\mathrm{a}}$ & $48.95^{\mathrm{a}}$ & $76.95^{\mathrm{a}}$ & ++ & $4.00^{\mathrm{a}}$ \\
\hline & CWG & $13.20^{\mathrm{b}}$ & $33.60^{\mathrm{b}}$ & $53.87^{\mathrm{c}}$ & +++ & $5.00^{\mathrm{b}}$ \\
\hline & CGG & $13.76^{\mathrm{b}}$ & $46.11^{\mathrm{a}}$ & $73.74^{\mathrm{a}}$ & + & $4.00^{\mathrm{a}}$ \\
\hline V.volvacea & PDA & $25.39^{\mathrm{b}}$ & $53.60^{\mathrm{b}}$ & $80.92^{\text {bc }}$ & ++++ & $4.00^{\mathrm{ab}}$ \\
\hline \multirow[t]{4}{*}{ CLSU strain } & RBG & $30.28^{\mathrm{b}}$ & $54.65^{\mathrm{b}}$ & $76.18^{\mathrm{c}}$ & ++ & $4.00^{\mathrm{b}}$ \\
\hline & PSG & $43.44^{\mathrm{a}}$ & $80.64^{\mathrm{a}}$ & $90.00^{\mathrm{a}}$ & ++ & $3.00^{\mathrm{a}}$ \\
\hline & CWG & $26.69^{b}$ & $54.32^{\mathrm{b}}$ & $86.03^{\mathrm{ab}}$ & +++ & $3.33^{\mathrm{c}}$ \\
\hline & CGG & $44.59^{\mathrm{a}}$ & $80.53^{\mathrm{a}}$ & $90.00^{\mathrm{a}}$ & + & $3.00^{\mathrm{ab}}$ \\
\hline C. cinerea & PDA & $20.25^{\mathrm{cd}}$ & $34.00^{\mathrm{b}}$ & $44.47^{\mathrm{a}}$ & ++++ & $6.33^{\mathrm{ab}}$ \\
\hline \multirow[t]{4}{*}{ Sto Domingo strain } & $\mathrm{RBG}$ & $22.73^{b}$ & $34.09^{\mathrm{b}}$ & $55.59^{\mathrm{a}}$ & ++ & $7.00^{\mathrm{b}}$ \\
\hline & PSG & $24.81^{\mathrm{a}}$ & $45.42^{\mathrm{a}}$ & $56.86^{\mathrm{a}}$ & ++ & $5.67^{\mathrm{a}}$ \\
\hline & CWG & $18.34^{\mathrm{d}}$ & $30.57^{\mathrm{b}}$ & $40.55^{\mathrm{a}}$ & +++ & $6.00^{\mathrm{ab}}$ \\
\hline & CGG & $21.75^{b c}$ & $33.89^{\mathrm{b}}$ & $44.48^{\mathrm{a}}$ & + & $6.33^{\mathrm{ab}}$ \\
\hline C.cinerea & PDA & $16.51^{\mathrm{a}}$ & $24.26^{\mathrm{a}}$ & $37.15^{\mathrm{a}}$ & ++++ & $6.33^{\mathrm{d}}$ \\
\hline \multirow[t]{4}{*}{ CLSU strain } & $\mathrm{RBG}$ & $14.59^{\mathrm{b}}$ & $22.31^{b c}$ & $35.30^{\mathrm{ab}}$ & ++ & $7.33^{\mathrm{bc}}$ \\
\hline & PSG & $15.06^{\mathrm{ab}}$ & $21.46^{\mathrm{c}}$ & $33.91^{\mathrm{b}}$ & ++ & $8.33^{\mathrm{a}}$ \\
\hline & CWG & $15.55^{\mathrm{ab}}$ & $23.45^{\mathrm{ab}}$ & $36.82^{\mathrm{ab}}$ & +++ & $6.67^{\mathrm{dc}}$ \\
\hline & CGG & $12.93^{c}$ & $22.41^{b c}$ & $34.25^{\mathrm{ab}}$ & + & $8.00^{\mathrm{ab}}$ \\
\hline S. commune & PDA & $14.92^{\mathrm{a}}$ & $23.91^{\mathrm{a}}$ & $33.63^{\mathrm{a}}$ & ++++ & $8.67^{\mathrm{ab}}$ \\
\hline \multirow[t]{4}{*}{ CLSU strain } & $\mathrm{RBG}$ & $12.30^{\mathrm{bc}}$ & $17.82^{\mathrm{b}}$ & $28.10^{\mathrm{bc}}$ & +++ & $8.33^{\mathrm{b}}$ \\
\hline & PSG & $11.97^{\mathrm{cd}}$ & $16.33^{b c}$ & $24.18^{\mathrm{cd}}$ & ++ & $9.67^{\mathrm{a}}$ \\
\hline & CWG & $12.89^{b}$ & $17.89^{\mathrm{b}}$ & $28.71^{\mathrm{b}}$ & +++ & $6.67^{\mathrm{c}}$ \\
\hline & CGG & $11.18^{\mathrm{d}}$ & $14.79^{c}$ & $20.94^{\mathrm{d}}$ & + & $9.33^{\mathrm{ab}}$ \\
\hline S. commune & PDA & $14.08^{\mathrm{a}}$ & $19.06^{\mathrm{a}}$ & $21.99^{\mathrm{ab}}$ & ++++ & $7.33^{\mathrm{ab}}$ \\
\hline \multirow[t]{4}{*}{ Bataan strain } & $\mathrm{RBG}$ & $12.60^{\mathrm{b}}$ & $16.83^{\mathrm{a}}$ & $21.56^{\mathrm{ab}}$ & ++ & $7.00^{\mathrm{ab}}$ \\
\hline & PSG & $12.92^{\mathrm{b}}$ & $17.69^{\mathrm{a}}$ & $22.05^{\mathrm{ab}}$ & ++ & $8.00^{\mathrm{ab}}$ \\
\hline & CWG & $13.32^{\mathrm{ab}}$ & $17.33^{\mathrm{a}}$ & $23.32^{\mathrm{a}}$ & +++ & $6.33^{\mathrm{b}}$ \\
\hline & CGG & $13.07^{\mathrm{b}}$ & $17.38^{\mathrm{a}}$ & $19.46^{\mathrm{b}}$ & + & $8.33^{\mathrm{a}}$ \\
\hline \multirow[t]{5}{*}{ P. cystidiosus } & PDA & $11.55^{\mathrm{a}}$ & $16.69^{\mathrm{a}}$ & $22.38^{\mathrm{a}}$ & ++++ & $11.00^{\mathrm{b}}$ \\
\hline & $\mathrm{RBG}$ & $11.38^{\mathrm{a}}$ & $15.11^{\mathrm{b}}$ & $20.18^{\mathrm{b}}$ & ++ & $13.67^{\mathrm{a}}$ \\
\hline & PSG & $11.13^{\mathrm{a}}$ & $15.36^{\mathrm{b}}$ & $20.04^{\mathrm{b}}$ & ++ & $13.00^{\mathrm{a}}$ \\
\hline & CWG & $11.62^{\mathrm{a}}$ & $15.57^{\mathrm{b}}$ & $21.49^{\mathrm{ab}}$ & +++ & $11.00^{\mathrm{b}}$ \\
\hline & CGG & $11.01^{\mathrm{a}}$ & $15.48^{\mathrm{b}}$ & $20.79^{b}$ & + & $12.67^{\mathrm{a}}$ \\
\hline L. sajor caju & PDA & $17.06^{\mathrm{a}}$ & $33.99^{\mathrm{a}}$ & $53.49^{\mathrm{a}}$ & ++++ & $5.33^{\mathrm{b}}$ \\
\hline
\end{tabular}




\begin{tabular}{|c|c|c|c|c|c|c|}
\hline \multirow[b]{2}{*}{ Mushroom Species } & \multirow{2}{*}{$\begin{array}{l}\text { Culture } \\
\text { media }\end{array}$} & \multicolumn{3}{|c|}{$\begin{array}{c}\text { Secondary Mycelial Growth } \\
\text { Diameter }(\mathbf{m m}) \\
\end{array}$} & \multirow[t]{2}{*}{$\begin{array}{l}\text { Mycelial } \\
\text { Density }\end{array}$} & \multirow[t]{2}{*}{$\begin{array}{c}\text { Incubation } \\
\text { Period (days) }\end{array}$} \\
\hline & & Day 1 & Day 2 & Day 3 & & \\
\hline \multirow{9}{*}{ A. polytricha } & RBG & $16.38^{\mathrm{ab}}$ & $28.65^{b}$ & $45.89^{\mathrm{c}}$ & +++ & $6.67^{\mathrm{a}}$ \\
\hline & PSG & $14.89^{\mathrm{bc}}$ & $28.29^{\mathrm{b}}$ & $45.59^{c}$ & ++ & $6.67^{\mathrm{a}}$ \\
\hline & CWG & $15.84^{\mathrm{abc}}$ & $29.14^{\mathrm{b}}$ & $50.32^{\mathrm{ab}}$ & ++++ & $5.67^{\mathrm{b}}$ \\
\hline & CGG & $14.43^{\mathrm{c}}$ & $26.84^{\mathrm{b}}$ & $47.67^{\mathrm{bc}}$ & + & $6.00^{\mathrm{ab}}$ \\
\hline & PDA & $14.45^{\mathrm{ab}}$ & $18.41^{\mathrm{a}}$ & $22.30^{\mathrm{a}}$ & ++++ & $7.00^{\mathrm{b}}$ \\
\hline & RBG & $12.70^{\mathrm{cd}}$ & $15.50^{\mathrm{c}}$ & $20.05^{\mathrm{b}}$ & ++ & $8.00^{\mathrm{a}}$ \\
\hline & PSG & $13.61^{\mathrm{bc}}$ & $15.52^{c}$ & $20.47^{\mathrm{b}}$ & ++ & $7.67^{\mathrm{ab}}$ \\
\hline & CWG & $15.41^{\mathrm{a}}$ & $17.77^{\mathrm{ab}}$ & $20.83^{\mathrm{ab}}$ & +++ & $7.33^{\mathrm{ab}}$ \\
\hline & CGG & $11.73^{\mathrm{d}}$ & $16.07^{\mathrm{bc}}$ & $20.00^{\mathrm{b}}$ & + & $7.33^{\mathrm{ab}}$ \\
\hline
\end{tabular}

Mycelial density: very thin (+), thin (++), thick (+++), very thick (++++).

Means with the same letter are not significantly different.

\section{pH}

The $\mathrm{pH}$ of the culture medium is very important factor for mycelial growth of fungi (Kibar \& Peksen, 2011). Generally, mushrooms can grow in a wide range of $\mathrm{pH}$ of the medium. Table 2 shows the mycelial diameter, mycelial density and incubation period at different $\mathrm{pH}$ levels of the culture medium. It can be observed that the mycelia of different macrofungi species can grow at different $\mathrm{pH}$ levels ranging from slightly acidic, neutral and slightly alkaline medium. Most of the mushroom species produced maximum mycelial diameter and very thick mycelial density in slightly acidic to neutral $\mathrm{pH}$ (pH 6 to 7). This finding is congruent to the observation of Klomklung et al. (2014) who disclosed that Pleurotus giganteus, Lentinus conatus and Lentinus roseus can grew fairly well in acidic, neutral and alkaline environment ( $\mathrm{pH} 5$ to 8). The result of the present study confirms the finding of Yang et al. (2003) who reported that the mycelial of various species of mushrooms can grow over a wide range of $\mathrm{pH}$. Imtiaj et al. (2008) also reported that mushrooms have a wide range of $\mathrm{pH}$ (5 to 9) for their mycelial growth but mostly favorable $\mathrm{pH}$ was between 6 and 7. Moreover, Jo et al. (2009) disclosed that $\mathrm{pH}$ of 6 to 9 was suitable for the growth of Ganoderma applanatum. Likewise, Chandana et al. (2008) reported that G. lucidum Korean strain grew over a wide range of $\mathrm{pH}$ (5 to 9) but the optimum growth was obtained at $\mathrm{pH}$ 5. Chandra and Pukayastha (1997) and Jonathan et al (2007) also reported that $A$. campestris and $V$. esculenta showed good quality mycelial growth at $\mathrm{pH} 6$. Fasola et al. (2007) reported that the mycelial growth of Volvariella speciosa was obtained in the $\mathrm{pH}$ of 3 to 9.

\section{Illumination}

According to Chang and Miles (2004) the growth of most fungi is not sensitive to light, although strong light may inhibit or even kill the mycelia. In this study, the influence of illumination was evaluated by subjecting the mycelia to light and dark conditions. Table 3 shows that all macrofungi species can grow in both illumination conditions. Generally, most macrofungi species produced larger mycelial diameter in lighted condition compared to those incubated in dark condition. This finding is congruent to the previous report on the positive effect of light on mycelial growth L. tigrinus (Dulay et al. 2012) and V. volvacea (Reyes et al. 1998). While, both strains of L. tigrinus, V. volvacea and $C$. cinerea incubated in dark condition registered wider mycelial growth than those cultured in lighted conditions. Similar findings were reported by Bustillos et al. (2014) in Paneolus antillarium and Paneolus cyanescens. This confirms previous reports that light is not necessary for mycelial formation in C. reinakeana (Reyes et al. 1997) and C. comatus (Reyes et al. 2009). Sung et al. (2011) observed no obvious difference in the colony diameter of Ophiocordiceps longissima between light and dark conditions

There is no significant difference in mycelial density and incubation period of different macrofungi species when incubated in both lighted and dark conditions. 
Table 2 Mycelial diameter, mycelia density and incubation period of different mushroom species at different $\mathrm{pH}$ levels.

\begin{tabular}{|c|c|c|c|c|c|c|}
\hline \multirow[t]{2}{*}{ Mushroom Species } & \multirow[t]{2}{*}{ pH } & \multicolumn{3}{|c|}{$\begin{array}{l}\text { Secondary Mycelial Growth Diameter } \\
\qquad(\mathrm{mm})\end{array}$} & \multirow[t]{2}{*}{$\begin{array}{l}\text { Mycelial } \\
\text { Density }\end{array}$} & \multirow[t]{2}{*}{$\begin{array}{l}\text { Incubation } \\
\text { Period (days) }\end{array}$} \\
\hline & & Day 1 & Day 2 & Day 3 & & \\
\hline \multirow[t]{5}{*}{ G. lucidum strain A } & 6 & $14.78^{\mathrm{a}}$ & $24.53^{\mathrm{ab}}$ & $39.80^{\mathrm{a}}$ & ++++ & $7.67^{\mathrm{a}}$ \\
\hline & 6.5 & $13.72^{\mathrm{ab}}$ & $27.73^{\mathrm{ab}}$ & $50.26^{\mathrm{a}}$ & ++++ & $6.00^{\mathrm{b}}$ \\
\hline & 7 & $14.77^{\mathrm{ab}}$ & $30.07^{\mathrm{a}}$ & $48.13^{\mathrm{a}}$ & +++ & $6.00^{\mathrm{b}}$ \\
\hline & 7.5 & $12.40^{\mathrm{b}}$ & $20.71^{\mathrm{b}}$ & $39.81^{\mathrm{a}}$ & +++ & $7.00^{\mathrm{ab}}$ \\
\hline & 8 & $13.82^{\mathrm{ab}}$ & $29.59^{\mathrm{a}}$ & $47.53^{\mathrm{a}}$ & +++ & $6.00^{\mathrm{b}}$ \\
\hline \multirow[t]{5}{*}{ G. lucidum strain B } & 6 & $14.77^{\mathrm{b}}$ & $33.51^{\mathrm{a}}$ & $56.28^{\mathrm{a}}$ & ++++ & $5.00^{\mathrm{b}}$ \\
\hline & 6.5 & $14.72^{\mathrm{b}}$ & $31.98^{\mathrm{ab}}$ & $53.80^{\mathrm{a}}$ & ++++ & $6.00^{\mathrm{ab}}$ \\
\hline & 7 & $16.62^{\mathrm{a}}$ & $33.58^{\mathrm{a}}$ & $56.21^{\mathrm{a}}$ & ++++ & $5.00^{\mathrm{b}}$ \\
\hline & 7.5 & $14.63^{\mathrm{b}}$ & $30.40^{\mathrm{ab}}$ & $54.45^{\mathrm{a}}$ & +++ & $6.33^{\mathrm{ab}}$ \\
\hline & 8 & $12.56^{\mathrm{c}}$ & $28.50^{\mathrm{b}}$ & $50.63^{\mathrm{b}}$ & +++ & $6.67^{\mathrm{b}}$ \\
\hline L. tigrinus & 6 & $11.54^{\mathrm{ab}}$ & $25.88^{\mathrm{a}}$ & $44.50^{\mathrm{a}}$ & +++ & $6.00^{\mathrm{a}}$ \\
\hline \multirow[t]{4}{*}{ CLSU strain A } & 6.5 & $12.04^{\mathrm{a}}$ & $26.23^{\mathrm{a}}$ & $40.08^{\mathrm{ab}}$ & +++ & $7.33^{\mathrm{b}}$ \\
\hline & 7 & $10.97^{\mathrm{b}}$ & $19.45^{\mathrm{b}}$ & $31.85^{\mathrm{c}}$ & +++ & $7.67^{\mathrm{b}}$ \\
\hline & 7.5 & $11.12^{\mathrm{b}}$ & $20.82^{\mathrm{b}}$ & $34.86^{\mathrm{bc}}$ & ++++ & $7.33^{\mathrm{b}}$ \\
\hline & 8 & $10.93^{\mathrm{b}}$ & $18.81^{\mathrm{b}}$ & $30.19^{c}$ & ++++ & $7.67^{\mathrm{b}}$ \\
\hline L. tigrinus & 6 & $12.01^{\mathrm{a}}$ & $20.30^{\mathrm{a}}$ & $47.16^{\mathrm{a}}$ & +++ & $6.00^{\mathrm{b}}$ \\
\hline \multirow[t]{4}{*}{ CLSU strain B } & 6.5 & $11.29^{\mathrm{b}}$ & $23.28^{\mathrm{a}}$ & $40.32^{\mathrm{a}}$ & +++ & $7.00^{\mathrm{ab}}$ \\
\hline & 7 & $11.07^{\mathrm{b}}$ & $22.49^{\mathrm{a}}$ & $37.04^{\mathrm{a}}$ & +++ & $7.67^{\mathrm{a}}$ \\
\hline & 7.5 & $11.14^{\mathrm{b}}$ & $23.11^{\mathrm{a}}$ & $42.15^{\mathrm{a}}$ & ++++ & $6.00^{\mathrm{b}}$ \\
\hline & 8 & $11.27^{\mathrm{b}}$ & $21.09^{\mathrm{a}}$ & $37.87^{\mathrm{a}}$ & ++++ & $6.67^{\mathrm{ab}}$ \\
\hline V. volvacea & 6 & $17.15^{\mathrm{c}}$ & $44.40^{c}$ & $66.17^{\mathrm{c}}$ & +++ & $5.00^{\mathrm{a}}$ \\
\hline \multirow{4}{*}{ Rang-ayan strain } & 6.5 & $18.88^{\mathrm{b}}$ & $46.35^{\mathrm{bc}}$ & $71.99^{\mathrm{ab}}$ & +++ & $5.00^{\mathrm{a}}$ \\
\hline & 7 & $15.82^{\mathrm{c}}$ & $50.74^{\mathrm{a}}$ & $76.15^{\mathrm{a}}$ & +++ & $5.00^{\mathrm{a}}$ \\
\hline & 7.5 & $18.88^{\mathrm{b}}$ & $48.02^{\mathrm{b}}$ & $72.32^{\mathrm{ab}}$ & ++++ & $4.00^{\mathrm{b}}$ \\
\hline & 8 & $22.40^{\mathrm{a}}$ & $46.87^{\mathrm{b}}$ & $68.92^{\mathrm{bc}}$ & ++++ & $4.00^{\mathrm{b}}$ \\
\hline V.volvacea & 6 & $25.40^{\mathrm{b}}$ & $73.54^{\mathrm{a}}$ & $89.45^{\mathrm{a}}$ & +++ & $3.33^{\mathrm{a}}$ \\
\hline \multirow[t]{4}{*}{ CLSU strain } & 6.5 & $30.28^{\mathrm{b}}$ & $67.07^{\mathrm{a}}$ & $88.42^{\mathrm{a}}$ & +++ & $3.67^{\mathrm{a}}$ \\
\hline & 7 & $43.44^{\mathrm{a}}$ & $67.36^{\mathrm{a}}$ & $88.08^{\mathrm{a}}$ & +++ & $3.67^{\mathrm{a}}$ \\
\hline & 7.5 & $26.69^{\mathrm{b}}$ & $66.83^{\mathrm{a}}$ & $87.75^{\mathrm{a}}$ & ++++ & $3.67^{\mathrm{a}}$ \\
\hline & 8 & $44.59^{\mathrm{a}}$ & $83.46^{\mathrm{a}}$ & $90.00^{\mathrm{a}}$ & ++++ & $3.00^{\mathrm{a}}$ \\
\hline C. comatus & 6 & $16.69^{\mathrm{a}}$ & $32.78^{\mathrm{a}}$ & $45.80^{\mathrm{a}}$ & +++ & $7.67^{\mathrm{b}}$ \\
\hline \multirow[t]{4}{*}{ Sto Domingo strain } & 6.5 & $13.35^{\mathrm{c}}$ & $27.62^{\mathrm{b}}$ & $40.93^{\mathrm{b}}$ & +++ & $7.67^{\mathrm{b}}$ \\
\hline & 7 & $15.08^{\mathrm{b}}$ & $27.35^{\mathrm{b}}$ & $39.42^{\mathrm{b}}$ & +++ & $7.67^{\mathrm{b}}$ \\
\hline & 7.5 & $15.51^{\mathrm{ab}}$ & $31.70^{\mathrm{a}}$ & $48.13^{\mathrm{a}}$ & ++++ & $5.00^{\mathrm{a}}$ \\
\hline & 8 & $16.81^{\mathrm{a}}$ & $31.41^{\mathrm{a}}$ & $45.07^{\mathrm{a}}$ & ++++ & $7.67^{\mathrm{b}}$ \\
\hline C.cinerea & 6 & $16.33^{\mathrm{a}}$ & $32.37^{\mathrm{a}}$ & $45.84^{\mathrm{a}}$ & +++ & $6.67^{\mathrm{a}}$ \\
\hline \multirow[t]{4}{*}{ CLSU strain } & 6.5 & $14.16^{\mathrm{b}}$ & $27.63^{\mathrm{b}}$ & $41.30^{\mathrm{b}}$ & +++ & $7.33^{\mathrm{a}}$ \\
\hline & 7 & $15.61^{\mathrm{a}}$ & $26.68^{\mathrm{b}}$ & $39.58^{\mathrm{b}}$ & +++ & $7.67^{\mathrm{a}}$ \\
\hline & 7.5 & $16.14^{\mathrm{a}}$ & $31.08^{\mathrm{a}}$ & $47.45^{\mathrm{a}}$ & ++++ & $7.00^{\mathrm{a}}$ \\
\hline & 8 & $16.86^{\mathrm{a}}$ & $30.88^{\mathrm{a}}$ & $44.98^{\mathrm{a}}$ & ++++ & $7.00^{\mathrm{a}}$ \\
\hline S. commune & 6 & $14.44^{\mathrm{a}}$ & $18.44^{\mathrm{a}}$ & $33.51^{\mathrm{a}}$ & ++++ & $8.33^{\mathrm{ab}}$ \\
\hline \multirow[t]{4}{*}{ CLSU strain } & 6.5 & $13.72^{\mathrm{ab}}$ & $17.19^{\mathrm{a}}$ & $31.98^{\mathrm{ab}}$ & ++++ & $7.33^{\mathrm{ab}}$ \\
\hline & 7 & $14.18^{\mathrm{ab}}$ & $19.12^{\mathrm{a}}$ & $33.58^{\mathrm{a}}$ & ++++ & $8.67^{\mathrm{ab}}$ \\
\hline & 7.5 & $12.40^{\mathrm{b}}$ & $18.59^{\mathrm{a}}$ & $30.40^{\mathrm{ab}}$ & +++ & $7.00^{\mathrm{a}}$ \\
\hline & 8 & $13.82^{\mathrm{ab}}$ & $18.52^{\mathrm{a}}$ & $28.50^{\mathrm{b}}$ & +++ & $9.00^{\mathrm{a}}$ \\
\hline S. commune & 6 & $14.77^{\mathrm{b}}$ & $17.48^{\mathrm{b}}$ & $33.51^{\mathrm{a}}$ & ++++ & $5.33^{\mathrm{a}}$ \\
\hline \multirow[t]{4}{*}{ Bataan strain } & 6.5 & $14.72^{\mathrm{b}}$ & $17.24^{\mathrm{b}}$ & $31.98^{\mathrm{ab}}$ & +++ & $7.33^{\mathrm{a}}$ \\
\hline & 7 & $16.62^{\mathrm{a}}$ & $19.10^{\mathrm{a}}$ & $33.58^{\mathrm{a}}$ & ++++ & $8.33^{\mathrm{a}}$ \\
\hline & 7.5 & $14.63^{\mathrm{b}}$ & $17.68^{\mathrm{b}}$ & $30.40^{\mathrm{ab}}$ & +++ & $7.33^{\mathrm{a}}$ \\
\hline & 8 & $12.56^{\mathrm{c}}$ & $18.30^{\mathrm{ab}}$ & $28.50^{\mathrm{b}}$ & +++ & $7.33^{\mathrm{a}}$ \\
\hline \multirow[t]{5}{*}{ P. cystidiosus } & 6 & $11.83 \mathrm{a}$ & $14.49^{\mathrm{a}}$ & $17.06^{\mathrm{a}}$ & +++ & $12.00^{\mathrm{a}}$ \\
\hline & 6.5 & $11.53^{\mathrm{a}}$ & $14.70^{\mathrm{a}}$ & $16.39^{\mathrm{a}}$ & +++ & $13.33^{\mathrm{a}}$ \\
\hline & 7 & $11.44^{\mathrm{a}}$ & $14.04^{\mathrm{a}}$ & $16.05^{\mathrm{a}}$ & +++ & $13.33^{\mathrm{a}}$ \\
\hline & 7.5 & $11.35^{\mathrm{a}}$ & $13.77^{\mathrm{a}}$ & $15.70^{\mathrm{a}}$ & ++++ & $11.67^{\mathrm{a}}$ \\
\hline & 8 & $11.49^{\mathrm{a}}$ & $13.59^{\mathrm{a}}$ & $15.95^{\mathrm{a}}$ & ++++ & $12.33^{\mathrm{a}}$ \\
\hline
\end{tabular}




\begin{tabular}{|c|c|c|c|c|c|c|}
\hline \multirow[t]{2}{*}{ Mushroom Species } & \multirow[t]{2}{*}{ pH } & \multicolumn{3}{|c|}{$\begin{array}{l}\text { Secondary Mycelial Growth Diameter } \\
(\mathbf{m m})\end{array}$} & \multirow[t]{2}{*}{$\begin{array}{l}\text { Mycelial } \\
\text { Density }\end{array}$} & \multirow[t]{2}{*}{$\begin{array}{l}\text { Incubation } \\
\text { Period (days) }\end{array}$} \\
\hline & & Day 1 & Day 2 & Day 3 & & \\
\hline \multirow[t]{5}{*}{ L. sajor caju } & 6 & $15.99^{\mathrm{ab}}$ & $27.46^{\mathrm{a}}$ & $44.50^{\mathrm{a}}$ & ++++ & $5.67^{\mathrm{a}}$ \\
\hline & 6.5 & $15.96^{\mathrm{ab}}$ & $26.76^{\mathrm{a}}$ & $43.41^{\mathrm{a}}$ & ++++ & $6.00^{\mathrm{a}}$ \\
\hline & 7 & $16.96^{\mathrm{a}}$ & $28.06^{\mathrm{a}}$ & $44.10^{\mathrm{a}}$ & +++ & $6.33^{\mathrm{a}}$ \\
\hline & 7.5 & $15.41^{\mathrm{ab}}$ & $27.44^{\mathrm{a}}$ & $43.81^{\mathrm{a}}$ & +++ & $6.33^{\mathrm{a}}$ \\
\hline & 8 & $15.08^{\mathrm{b}}$ & $28.03^{\mathrm{a}}$ & $42.41^{\mathrm{a}}$ & +++ & $6.33^{\mathrm{a}}$ \\
\hline \multirow[t]{5}{*}{ A. polytricha } & 6 & $11.93^{\mathrm{c}}$ & $17.15^{\mathrm{bc}}$ & $22.57^{\mathrm{a}}$ & +++ & $7.00^{\mathrm{a}}$ \\
\hline & 6.5 & $13.47^{\mathrm{bc}}$ & $18.64^{\mathrm{ab}}$ & $23.16^{\mathrm{a}}$ & +++ & $7.67^{\mathrm{a}}$ \\
\hline & 7 & $14.38^{\mathrm{ab}}$ & $16.56^{\mathrm{c}}$ & $22.38^{\mathrm{a}}$ & +++ & $7.67^{\mathrm{a}}$ \\
\hline & 7.5 & $15.41^{\mathrm{a}}$ & $18.88^{\mathrm{a}}$ & $23.24^{\mathrm{a}}$ & ++++ & $7.00^{\mathrm{a}}$ \\
\hline & 8 & $15.10^{\mathrm{ab}}$ & $18.76^{\mathrm{ab}}$ & $22.80^{\mathrm{a}}$ & ++++ & $7.67^{\mathrm{a}}$ \\
\hline
\end{tabular}

Mycelial density: very thin (+), thin (++), thick (+++), very thick (++++).

Means with the same letter are not significantly different.

Table 3 Mycelial diameter, mycelial density and incubation period of different mushroom species in lighted and dark conditions.

\begin{tabular}{|c|c|c|c|c|c|c|}
\hline \multirow{2}{*}{$\begin{array}{l}\text { Mushroom } \\
\text { Species }\end{array}$} & \multirow{2}{*}{$\begin{array}{l}\text { Illumination } \\
\text { Conditions }\end{array}$} & \multicolumn{3}{|c|}{$\begin{array}{c}\text { Secondary Mycelial Growth } \\
\text { Diameter }(\mathbf{m m})\end{array}$} & \multirow[t]{2}{*}{$\begin{array}{c}\text { Mycelial } \\
\text { Density }\end{array}$} & \multirow[t]{2}{*}{$\begin{array}{l}\text { Incubation } \\
\text { Period } \\
\text { (days) }\end{array}$} \\
\hline & & Day 1 & Day 2 & Day 3 & & \\
\hline \multirow[t]{2}{*}{ G. lucidum strain $\mathrm{A}$} & Lighted & $15.59^{\mathrm{a}}$ & $33.44^{\mathrm{a}}$ & $57.28^{\mathrm{a}}$ & +++ & $5.00^{\mathrm{a}}$ \\
\hline & Dark & $15.08^{\mathrm{a}}$ & $34.75^{\mathrm{a}}$ & $61.32^{\mathrm{a}}$ & +++ & $5.00^{\mathrm{a}}$ \\
\hline \multirow[t]{2}{*}{ G. lucidum strain B } & Lighted & $14.80^{\mathrm{a}}$ & $33.76^{\mathrm{a}}$ & $58.57^{\mathrm{b}}$ & +++ & $5.00^{\mathrm{a}}$ \\
\hline & Dark & $14.62^{\mathrm{a}}$ & $34.04^{\mathrm{a}}$ & $61.94^{\mathrm{a}}$ & +++ & $5.00^{\mathrm{a}}$ \\
\hline \multirow{2}{*}{$\begin{array}{l}\text { L. tigrinus } \\
\text { CLSU strain A }\end{array}$} & Lighted & $12.57^{\mathrm{a}}$ & $24.95^{\mathrm{a}}$ & $38.92^{\mathrm{b}}$ & +++ & $7.00^{\mathrm{a}}$ \\
\hline & Dark & $12.45^{\mathrm{a}}$ & $24.28^{\mathrm{a}}$ & $48.63^{\mathrm{a}}$ & +++ & $6.00^{\mathrm{a}}$ \\
\hline \multirow{2}{*}{$\begin{array}{l}\text { L. tigrinus } \\
\text { CLSU strain B }\end{array}$} & Lighted & $13.24^{\mathrm{a}}$ & $29.52^{\mathrm{a}}$ & $50.63^{\mathrm{a}}$ & +++ & $6.00^{\mathrm{a}}$ \\
\hline & Dark & $12.69^{\mathrm{a}}$ & $29.99^{\mathrm{a}}$ & $53.96^{\mathrm{a}}$ & +++ & $6.00^{\mathrm{a}}$ \\
\hline \multirow{2}{*}{$\begin{array}{l}\text { V. volvacea } \\
\text { Rang-ayan strain }\end{array}$} & Lighted & $21.37^{\mathrm{a}}$ & $49.36^{\mathrm{a}}$ & $75.55^{\mathrm{a}}$ & +++ & $4.00^{\mathrm{a}}$ \\
\hline & Dark & $22.73^{\mathrm{a}}$ & $46.77^{\mathrm{a}}$ & $75.98^{\mathrm{a}}$ & +++ & $4.00^{\mathrm{a}}$ \\
\hline \multirow{2}{*}{$\begin{array}{l}\text { V. volvacea } \\
\text { CLSU strain }\end{array}$} & Lighted & $24.55^{\mathrm{a}}$ & $63.72^{\mathrm{a}}$ & $87.11^{\mathrm{a}}$ & +++ & $3.33^{\mathrm{a}}$ \\
\hline & Dark & $23.61^{\mathrm{a}}$ & $62.98^{\mathrm{a}}$ & $86.99^{\mathrm{a}}$ & +++ & $3.33^{\mathrm{a}}$ \\
\hline \multirow{4}{*}{$\begin{array}{l}\text { C. cinerea } \\
\text { Sto. Domingo } \\
\text { strain } \\
\text { C. cinerea } \\
\text { CLSU strain }\end{array}$} & Lighted & $18.64^{\mathrm{a}}$ & $2.53^{\mathrm{a}}$ & $43.56^{\mathrm{a}}$ & +++ & $7.00^{\mathrm{a}}$ \\
\hline & Dark & $18.54^{\mathrm{a}}$ & $33.23^{\mathrm{a}}$ & $46.47^{\mathrm{a}}$ & +++ & $7.00^{\mathrm{a}}$ \\
\hline & Lighted & $16.79^{\mathrm{a}}$ & $28.91^{\mathrm{a}}$ & $42.16^{\mathrm{a}}$ & +++ & $7.33^{\mathrm{a}}$ \\
\hline & Dark & $16.70^{\mathrm{a}}$ & $28.82^{\mathrm{a}}$ & $41.78^{\mathrm{a}}$ & +++ & $7.67^{\mathrm{a}}$ \\
\hline \multirow{2}{*}{$\begin{array}{l}\text { S. commune } \\
\text { CLSU strain }\end{array}$} & Lighted & $17.43^{\mathrm{a}}$ & $28.33^{\mathrm{a}}$ & $42.99^{\mathrm{a}}$ & +++ & $6.33^{\mathrm{a}}$ \\
\hline & Dark & $17.18^{\mathrm{a}}$ & $28.23^{\mathrm{a}}$ & $42.21^{\mathrm{b}}$ & +++ & $6.00^{\mathrm{a}}$ \\
\hline \multirow{2}{*}{$\begin{array}{l}\text { S. commune } \\
\text { Bataan strain }\end{array}$} & Lighted & $16.55^{\mathrm{a}}$ & $21.64^{\mathrm{a}}$ & $34.32^{\mathrm{a}}$ & +++ & $7.67^{\mathrm{a}}$ \\
\hline & Dark & $16.71^{\mathrm{a}}$ & $20.95^{\mathrm{a}}$ & $34.42^{\mathrm{a}}$ & +++ & $7.67^{\mathrm{a}}$ \\
\hline \multirow[t]{2}{*}{ P. cystidiosus } & Lighted & $12.09^{\mathrm{a}}$ & $13.93^{\mathrm{a}}$ & $15.79 \mathrm{a}$ & +++ & $11.33^{\mathrm{a}}$ \\
\hline & Dark & $12.33^{\mathrm{a}}$ & $13.35^{\mathrm{a}}$ & $15.14 \mathrm{a}$ & +++ & $11.67^{\mathrm{a}}$ \\
\hline \multirow[t]{2}{*}{ L. sajor caju } & Lighted & $17.43^{\mathrm{a}}$ & $28.33^{\mathrm{a}}$ & $42.99^{a}$ & +++ & $6.33^{\mathrm{a}}$ \\
\hline & Dark & $17.18^{\mathrm{a}}$ & $28.23^{\mathrm{a}}$ & $42.21^{\mathrm{b}}$ & +++ & $6.00^{\mathrm{a}}$ \\
\hline \multirow[t]{2}{*}{ A.polytricha } & Lighted & $13.93^{\mathrm{a}}$ & $17.72^{\mathrm{a}}$ & $24.26 \mathrm{a}$ & +++ & $7.33^{\mathrm{a}}$ \\
\hline & Dark & $13.68^{\mathrm{a}}$ & $16.85^{\mathrm{b}}$ & $23.96 \mathrm{a}$ & +++ & $7.33^{\mathrm{a}}$ \\
\hline
\end{tabular}

Mycelial density: very thin (+), thin (++), thick (+++), very thick (++++).

Means with the same letter are not significantly different. 
Table 4 Mycelial diameter, mycelial density and incubation period of different mushroom species at different incubation temperatures.

\begin{tabular}{|c|c|c|c|c|c|c|}
\hline \multirow{2}{*}{$\begin{array}{l}\text { Mushroom } \\
\text { Species }\end{array}$} & \multirow{2}{*}{$\begin{array}{l}\text { Incubation } \\
\text { Temperatures }\end{array}$} & \multicolumn{3}{|c|}{$\begin{array}{c}\text { Secondary Mycelial Growth } \\
\text { Diameter }(\mathrm{mm})\end{array}$} & \multirow[t]{2}{*}{$\begin{array}{l}\text { Mycelial } \\
\text { Density }\end{array}$} & \multirow[t]{2}{*}{$\begin{array}{c}\text { Incubation } \\
\text { Period } \\
\text { (days) }\end{array}$} \\
\hline & & Day 1 & Day 2 & Day 3 & & \\
\hline \multirow[t]{3}{*}{ G. lucidum strain $\mathrm{A}$} & $\begin{array}{l}\text { Refrigeration } \\
\left(9^{\circ} \mathrm{C}\right)\end{array}$ & $10.00^{\mathrm{b}}$ & $10.00^{\mathrm{c}}$ & $10.00^{\mathrm{c}}$ & N/A & N/A \\
\hline & Air-con $\left(23^{\circ} \mathrm{C}\right)$ & $13.69^{\mathrm{a}}$ & $31.63^{\mathrm{b}}$ & $51.04^{\mathrm{b}}$ & +++ & $5.00^{\mathrm{a}}$ \\
\hline & $\operatorname{Room}\left(32^{\circ} \mathrm{C}\right)$ & $13.72^{\mathrm{a}}$ & $33.64^{\mathrm{a}}$ & $58.48^{\mathrm{a}}$ & +++ & $5.00^{\mathrm{a}}$ \\
\hline \multirow[t]{3}{*}{ G. lucidum strain B } & $\begin{array}{l}\text { Refrigeration } \\
\left(9^{\circ} \mathrm{C}\right)\end{array}$ & $10.00^{\mathrm{b}}$ & $10.00^{\mathrm{c}}$ & $10.00^{\mathrm{c}}$ & N/A & N/A \\
\hline & Air-con $\left(23^{\circ} \mathrm{C}\right)$ & $15.43^{\mathrm{a}}$ & $31.24^{\mathrm{b}}$ & $53.08^{\mathrm{b}}$ & +++ & $5.00^{\mathrm{a}}$ \\
\hline & $\operatorname{Room}\left(32^{\circ} \mathrm{C}\right)$ & $15.72^{\mathrm{a}}$ & $33.59^{\mathrm{a}}$ & $57.86^{\mathrm{a}}$ & +++ & $5.00^{\mathrm{a}}$ \\
\hline \multirow[t]{3}{*}{$\begin{array}{l}\text { L. tigrinus } \\
\text { CLSU strain A }\end{array}$} & $\begin{array}{l}\text { Refrigeration } \\
\left(9^{\circ} \mathrm{C}\right)\end{array}$ & $10.00^{\mathrm{b}}$ & $10.00^{\mathrm{b}}$ & $10.00^{\mathrm{b}}$ & N/A & N/A \\
\hline & Air-con $\left(23^{\circ} \mathrm{C}\right)$ & $11.71^{\mathrm{a}}$ & $22.22^{\mathrm{a}}$ & $34.89^{\mathrm{a}}$ & +++ & $6.00^{\mathrm{a}}$ \\
\hline & $\operatorname{Room}\left(32^{\circ} \mathrm{C}\right)$ & $12.58^{\mathrm{a}}$ & $21.64^{\mathrm{a}}$ & $32.95^{\mathrm{a}}$ & +++ & $6.67^{\mathrm{a}}$ \\
\hline \multirow[t]{3}{*}{$\begin{array}{l}\text { L. tigrinus } \\
\text { CLSU strain B }\end{array}$} & $\begin{array}{l}\text { Refrigeration } \\
\left(9^{\circ} \mathrm{C}\right)\end{array}$ & $10.00^{\mathrm{c}}$ & $10.00^{\mathrm{b}}$ & $10.00^{\mathrm{c}}$ & N/A & N/A \\
\hline & Air-con $\left(23^{\circ} \mathrm{C}\right)$ & $12.23^{\mathrm{b}}$ & $24.21^{\mathrm{a}}$ & $35.70^{\mathrm{b}}$ & +++ & $6.33^{\mathrm{a}}$ \\
\hline & $\operatorname{Room}\left(32^{\circ} \mathrm{C}\right)$ & $13.21^{\mathrm{a}}$ & $26.62^{\mathrm{a}}$ & $45.35^{\mathrm{a}}$ & +++ & $6.00^{\mathrm{a}}$ \\
\hline \multirow[t]{3}{*}{$\begin{array}{l}\text { V. volvacea } \\
\text { Rang-ayan strain }\end{array}$} & $\begin{array}{l}\text { Refrigeration } \\
\left(9^{\circ} \mathrm{C}\right)\end{array}$ & $10.00^{\mathrm{b}}$ & $10.00^{\mathrm{b}}$ & $10.00^{\mathrm{c}}$ & N/A & N/A \\
\hline & Air-con $\left(23^{\circ} \mathrm{C}\right)$ & $17.72^{\mathrm{a}}$ & $39.22^{\mathrm{a}}$ & $71.28^{\mathrm{b}}$ & +++ & $4.00^{\mathrm{a}}$ \\
\hline & $\operatorname{Room}\left(32^{\circ} \mathrm{C}\right)$ & $20.93^{\mathrm{a}}$ & $42.00^{\mathrm{a}}$ & $77.92^{\mathrm{a}}$ & +++ & $4.00^{\mathrm{a}}$ \\
\hline \multirow[t]{3}{*}{$\begin{array}{l}\text { V. volvacea } \\
\text { CLSU strain }\end{array}$} & $\begin{array}{l}\text { Refrigeration } \\
\left(9^{\circ} \mathrm{C}\right)\end{array}$ & $10.00^{\mathrm{b}}$ & $10.00^{\mathrm{b}}$ & $10.00^{\mathrm{b}}$ & N/A & N/A \\
\hline & Air-con $\left(23^{\circ} \mathrm{C}\right)$ & $23.75^{\mathrm{a}}$ & $63.34^{\mathrm{a}}$ & $82.74^{\mathrm{a}}$ & +++ & $4.00^{\mathrm{a}}$ \\
\hline & $\operatorname{Room}\left(32^{\circ} \mathrm{C}\right)$ & $24.43^{\mathrm{a}}$ & $64.61^{\mathrm{a}}$ & $86.85^{\mathrm{a}}$ & +++ & $3.00^{\mathrm{b}}$ \\
\hline \multirow{3}{*}{$\begin{array}{l}\text { C. cinerea } \\
\text { Sto. Domingo } \\
\text { strain }\end{array}$} & $\begin{array}{l}\text { Refrigeration } \\
\left(9^{\circ} \mathrm{C}\right)\end{array}$ & $10.00^{\mathrm{c}}$ & $10.00^{\mathrm{c}}$ & $10.00^{\mathrm{c}}$ & N/A & N/A \\
\hline & Air-con $\left(23^{\circ} \mathrm{C}\right)$ & $15.48^{\mathrm{b}}$ & $29.29^{b}$ & $34.98^{\mathrm{b}}$ & +++ & $7.00^{\mathrm{a}}$ \\
\hline & $\operatorname{Room}\left(32^{\circ} \mathrm{C}\right)$ & $17.01^{\mathrm{a}}$ & $31.81^{\mathrm{a}}$ & $40.52^{\mathrm{a}}$ & +++ & $7.00^{\mathrm{a}}$ \\
\hline \multirow[t]{3}{*}{$\begin{array}{l}\text { C. cinerea } \\
\text { CLSU strain }\end{array}$} & $\begin{array}{l}\text { Refrigeration } \\
\left(9^{\circ} \mathrm{C}\right)\end{array}$ & $10.00^{\mathrm{b}}$ & $10.00^{\mathrm{b}}$ & $10.00^{\mathrm{b}}$ & N/A & N/A \\
\hline & Air-con $\left(23^{\circ} \mathrm{C}\right)$ & $16.98^{\mathrm{a}}$ & $29.05^{\mathrm{b}}$ & $42.36^{\mathrm{a}}$ & +++ & $7.33^{\mathrm{a}}$ \\
\hline & $\operatorname{Room}\left(32^{\circ} \mathrm{C}\right)$ & $17.26^{\mathrm{a}}$ & $29.54^{\mathrm{a}}$ & $42.29^{\mathrm{a}}$ & +++ & $7.67^{\mathrm{a}}$ \\
\hline \multirow[t]{3}{*}{$\begin{array}{l}\text { S. commune } \\
\text { CLSU strain }\end{array}$} & $\begin{array}{l}\text { Refrigeration } \\
\left(9^{\circ} \mathrm{C}\right)\end{array}$ & $10.00^{\mathrm{b}}$ & $10.00^{\mathrm{b}}$ & $10.00^{\mathrm{b}}$ & N/A & N/A \\
\hline & Air-con $\left(23^{\circ} \mathrm{C}\right)$ & $14.77^{\mathrm{a}}$ & $20.32^{\mathrm{a}}$ & $32.66^{\mathrm{a}}$ & +++ & $6.00^{\mathrm{b}}$ \\
\hline & $\operatorname{Room}\left(32^{\circ} \mathrm{C}\right)$ & $14.61^{\mathrm{a}}$ & $20.20^{\mathrm{a}}$ & $32.41^{\mathrm{a}}$ & +++ & $6.67^{\mathrm{a}}$ \\
\hline \multirow[t]{3}{*}{$\begin{array}{l}\text { S. commune } \\
\text { Bataan strain }\end{array}$} & $\begin{array}{l}\text { Refrigeration } \\
\left(9^{\circ} \mathrm{C}\right)\end{array}$ & $10.00^{\mathrm{b}}$ & $10.00^{\mathrm{b}}$ & $10.00^{\mathrm{b}}$ & N/A & N/A \\
\hline & Air-con $\left(23^{\circ} \mathrm{C}\right)$ & $16.79^{\mathrm{a}}$ & $21.26^{\mathrm{a}}$ & $33.26^{\mathrm{a}}$ & +++ & $6.67^{\mathrm{a}}$ \\
\hline & $\operatorname{Room}\left(32^{\circ} \mathrm{C}\right)$ & $17.15^{\mathrm{a}}$ & $21.26^{\mathrm{a}}$ & $34.47^{\mathrm{a}}$ & +++ & $6.33^{\mathrm{a}}$ \\
\hline \multirow[t]{3}{*}{ P. cystidiosus } & $\begin{array}{l}\text { Refrigeration } \\
\left(9^{\circ} \mathrm{C}\right)\end{array}$ & $10.00^{\mathrm{c}}$ & $10.00^{\mathrm{c}}$ & $10.00^{\mathrm{b}}$ & N/A & N/A \\
\hline & Air-con $\left(23^{\circ} \mathrm{C}\right)$ & $11.51^{\mathrm{a}}$ & $13.59^{\mathrm{a}}$ & $15.95^{\mathrm{a}}$ & +++ & $11.00^{\mathrm{a}}$ \\
\hline & $\operatorname{Room}\left(32^{\circ} \mathrm{C}\right)$ & $11.20^{\mathrm{b}}$ & $13.20^{\mathrm{b}}$ & $15.59^{\mathrm{a}}$ & +++ & $12.00^{\mathrm{a}}$ \\
\hline \multirow[t]{3}{*}{ L. sajor caju } & $\begin{array}{l}\text { Refrigeration } \\
\left(9^{\circ} \mathrm{C}\right)\end{array}$ & $10.00^{\mathrm{b}}$ & $10.00^{\mathrm{b}}$ & $10.00^{\mathrm{c}}$ & N/A & N/A \\
\hline & Air-con $\left(23^{\circ} \mathrm{C}\right)$ & $17.23^{\mathrm{a}}$ & $27.65^{\mathrm{a}}$ & $41.72^{\mathrm{b}}$ & +++ & $5.67^{\mathrm{b}}$ \\
\hline & $\operatorname{Room}\left(32^{\circ} \mathrm{C}\right)$ & $17.42^{\mathrm{a}}$ & $28.25^{\mathrm{a}}$ & $42.84^{\mathrm{a}}$ & +++ & $7.00^{\mathrm{a}}$ \\
\hline \multirow[t]{3}{*}{ A.polytricha } & $\begin{array}{l}\text { Refrigeration } \\
\left(9^{\circ} \mathrm{C}\right)\end{array}$ & $10.00^{\mathrm{b}}$ & $10.00^{\mathrm{b}}$ & $10.00^{\mathrm{b}}$ & N/A & N/A \\
\hline & Air-con $\left(23^{\circ} \mathrm{C}\right)$ & $13.50^{\mathrm{a}}$ & $16.75^{\mathrm{a}}$ & $24.60^{\mathrm{a}}$ & +++ & $7.67^{\mathrm{a}}$ \\
\hline & Room $\left(32^{\circ} \mathrm{C}\right)$ & $13.71^{\mathrm{a}}$ & $16.82^{\mathrm{a}}$ & $24.66^{\mathrm{a}}$ & +++ & $8.00^{\mathrm{a}}$ \\
\hline
\end{tabular}




\section{Temperature}

Among the different physical factors affecting mycelial growth, temperature is one of the most important. Hoa and Wang (2015) reported that temperature is important environmental factor for mycelial growth of fungi. According to Chang and Miles (2004) temperature extremes are important for the survival and distribution of a fungal species in natute. Mushroom mycelia grow well with the temperature range between 20 to $30{ }^{\circ} \mathrm{C}$ (Cho, 2004). In the present study, the effect of temperature on mycelial growth was evaluated using $32{ }^{\circ} \mathrm{C}, 23{ }^{\circ} \mathrm{C}$ and $9{ }^{\circ} \mathrm{C}$. It can be noticed in Table 4 that L. sajor caju, S. commune, V. volvacea, G. lucidum, L. tigrinus, A. polytricha and C. cinerea produced wider mycelial diameter and shorter incubation period than those incubated at $23{ }^{\circ} \mathrm{C}$. On the other hand, maximum mycelial diameter and shorter incubation period of L. sajor caju, S. commune, and $\mathrm{P}$. cystidiosus were recorded at $23{ }^{\circ} \mathrm{C}$. It is interesting to note that no mycelial growth was observed in all species incubated in refrigerated condition. Temperature requirement for mycelial growth varies according to the species of mushrooms. This result is congruent to the observation of Lin (2004) who reported that fungi can be classified based on temperature requirement for mycelial growth such as temperate, semi - temperate or tropical species. Some species favor lower temperature while others require higher temperature. In a similar study, Klomklung et al. (2014) reported that mushroom mycelia were able to grow at temperatures ranging from $20-30{ }^{\circ} \mathrm{C}$, with optimal growth temperatures of $30{ }^{\circ} \mathrm{C}$ and $25{ }^{\circ} \mathrm{C}$ for Lentinus and Pleurotus species, respectively. Since optimum mycelial growth was obtained in room and air conditioned temperature, the mushrooms evaluated in this study can be classified as tropical species. Gbolagade et al. (2006) reported that the temperature range for mycelial growth of Lentinus subnulus were $15^{\circ} \mathrm{C}$ to $40{ }^{\circ} \mathrm{C}$. The ability of this mushroom species to grow in this temperature range could explain its ability to survive in a warm tropical climate.

\section{Acknowledgement}

This research was funded by the Philippine Council for Health Research and Development (PCHRD), Department of Science and Technology (DOST).

\section{References}

Akyuz M, Onganer AN, Erecevit P, Kirbag K. 2010 - Antimicrobial activity of some edible mushrooms in the Eastern and Southeast Anatolia Region Turkey. Gazi University Journal of Science 23(2), 125-130.

Borlingame B, Mouille B, Charrondiere R. 2009 - Nutrients, bioactive non nutrients and anti-nutrients in potatoes. Journal of Food Composition and Analysis 22, 494-502.

Bustillos RG, Dulay RMR, Bauto JJ, Pascual F, Baltazar K, Bunag HW, Macatula A, Nicolas MA, Torres MAM, Nillosa NC, De La Cruz JC, Kalaw SP, Reyes RG - 2014. Mycochemical profile of mycelial and fruiting body of Panaeolus cyanescens and its optimal submerged culture conditions for antioxidant properties. International Journal of Pure and Applied Bioscience 2(6), 175-181.

Bustillos RG, Dulay RMR, Kalaw SP, Reyes RG. 2014 - Optimization of culture conditions for mycelia growth and basidiocarp production of Philippine strains of Panaelus antillarium and Panaelus cyanescens. Mycosphere 5(3), 398-404.

Chandana J, Ahmed I, Hur H, Lee GW, Lee TS, Lee UY. 2008 - Favorable culture conditions for mycelial growth of Korean wild strains in Ganoderma lucidum. Mycobiology 36 (1), 28-33.

Chandra A, Purkayastha RP. 1997 - Physiological studies on Indian mushrooms. Trans Br Mycol Soc. 69, 63-70.

Chang ST, Miles PG. 2004 - Mushroom cultivation, nutritive value, medicinal effect and environmental impact. $2^{\text {nd }}$ ed. USA, CRC Press. 477 p.

Cho SB. 2004 - What is Mushroom. In. Mushrooms Grower's Handbook. MushWorld -Heinart Inc., Seoul, Korea. pp 3-6. 
De Leon AM, Reyes RG and De La Cruz TEE. 2013 - Lentinus squarrosulus and Polyporus grammocephalus: Newly domesticated, wild edible macrofungi from the Philippines. Philipp Agric Scientists 96 (4), 411-418.

Dulay RMR, Arenas MC, Kalaw SP, Reyes RG and Cabrera EC. 2014 - Proximate composition and functionality of culinary-medicinal tiger saw gill mushroom, Lentinus tigrinus (higher basidiomycetes) from the Philippines. Int J Med Mushrooms 16(1), 85-94.

Dulay RMR, Cabalar AC, De Roxas MJB, Concepcion JMP, Cruz NE, Esmeralda M, Jimeniz N, Aguilar JC, De Guzman EJ, Santiago JQ, Samoy JR, Bustillos RG, Kalaw SP, RG Reyes. 2015. Proximate composition and antioxidant activity of Panaeolus antillarium, a wild copriphilous mushroom. Current Research in Environmental and Applied Mycology 5(1), 52-59.

Dulay RMR, Kalaw SP, Reyes RG, Cabrera EC and Alfonso NF. 20012 - Optimization of culture conditions for mycelia growth and basidiocarp production of Lentinus tigrinus (Bull) Fr., a new record of domesticate wild edible mushroom in the Philippines. Phil. Agric Scientists 95(3), $278-285$.

Eguchi F, Kalaw SP, Dulay RMR, Miyasawa N, Yoshimoto H, Seyama T, Reyes RG. 2015 - Nutrient composition and functional activity of different stages in the fruiting body development of Philippine paddy straw mushroom, Volvariella volvacea (Bull.Fr.) Sing. Adv. Environ. Biol. 9(22), 54-65.

Elsayid EA, Enshasy HE, Wadaan MAM, Aziz R. 2014 - Mushrooms a potential natural source of anti-inflammatory compounds for medicinal applications. Mediators of inflammation, 2014, 1 15.

Fasola TR, Gbolagade JS, Fasidi IO. 2007 - Nutritional requirement of Volvariella speciosa (Ff. Ex. Fr.) Singer, a Nigerian edible mushrooms. Food Chemistry 100, 904-908.

Fife B. 2008. Nutritional benefits of coconut water. http://www.litalee.com/shopexd.asp?id=388. (accessed May 12 2011).

Gbolagade JS, Fasidi IO, Ajayi EJ, Sobowale AA. 2006 - Effect of physico-chemical factors and semi synthetic media on vegetative growth of Lentinus subnulus (Berk), an edible mushroom from Nigeria. Food Chemistry 99, 742-747.

Hoa HT, CL Wang. 2015. The effects of temperature and nutritional conditions on mycelium growth of two oyster mushrooms (Pleurotus ostreatus and Pleurotus cystidiosus). Mycobiology 43(1), $14-23$.

Imtiaj A, Jayasinghe C, Lee GW, Lee TS. 2008 - 2009 - Comparative study of environmental and nutritional factors on mycelial growth of edible mushrooms. Journal of Culture Collections 97 105.

Jo WS, Chu YJ, Cho HD, Park SD, Yoo YB, Seok SJ. 2009 - Culture conditions for the mycelial growth of Ganoderma applanatum. Mycobiology 37(2), 94-102.

Jonathan SG, Fasidi IO, Ajayi EJ. 2004 - Physico-chemical studies on Volvariella esculent Mass (Singer), a Nigerian edible fungus. Food Chem. 85, 339-342.

Kalaw SP, RF Albinto. 2015. Growth performance and nutritional attributes of Pleurotus species grown on rice straw based formulations. Adv. Environ. Biol. 9(18), 72-81.

Kibar B, Peksen A. 2011 - Nutritional and environmental requirements for vegetative growth of edible ectomychorizal mushroom Tricholoma terreum. Zemdirbyste Agriculture 98(4), 409 - 414.

Klaus AS, Kozarski MS, Niksic MP. 2009. Influence of bioactive compounds extracted from mushroom Ganoderma lucidum on B and T cells. Proc. Nat. Sci. Matica Srpska Novi Sad, 116, 217-223.

Klomklung N, Karunarathna SC, Hyde KD, E Chukeatirote. 2014 - Optimal conditions of mycelial growth of three wild edible mushrooms from northern Thailand. Acta Biol Szeged 58(1), 3943.

Klomklung N, Karunarathna SC, Hyde KD. 2014 - Optimal conditions of mycelial growth of three wild edible mushrooms from northern Thailand. Acta Biologica Szegediensis 58, 39-43.

Lin Z. 2004 - Grass (Juncao). In, Mushroom grower's handbook 1: Oyster mushroom cultivation. Seoul, Korea: MushWorld-Heineart Inc. 107-113. 
Puttaraju N, Venkateshaiah SU, Darmesh SM, Urs SMN, Somasundaram R. 2006 - Antioxidant activity of indigenous edible mushrooms. Journal of Agriculture and Food Chemistry 54 (26), 9764-9772.

Ragasa CY, Tan MCS, Reyes RG, Brkljaca R, Urban S. 2016. Chemical constituents of Pleurotus djamor. Der Pharma Chemica 892, 343-346.

Reyes RG, Eguchi F, Iijima T, Higaki M. 1997 - Collybia reinakeana, a wild edible mushroomfrom the forest of Puncan, Nueva Ecija, Philippines. Mushroom Science and Biotechnology 15(2), 99-102.

Reyes RG, Eguchi F, Iijima T, Higaki M. 1998. Physiological considerations for the efficient colonization of fukurotake, Volvariella volvacea. Journal of Wood Science 44, 408-413.

Reyes RG, Kalaw SP, Dulay RMR, Yoshimoto H, Miyazawa N, Seyama T, Eguchi F. 2013 Philippine native and exotic species of edible mushroom grown on rice straw based formulation exhibit nutraceutical properties. Phil. Agric. Scientists 96(2), 198-204.

Reyes RG, Lopez LMA, Kumakura L, Kalaw SP, Kikukawa TEF. 2009 - Coprinus comatus, a newly domesticated wild nutriceutical mushroom in the Philippines. Journal of Agricultural Technology 5(2), 299-316.

Sung GH, Shrestha B, Han SK, Sung JM. 2011 - Growth and cultural characteristics of Ophiocordyceps longissima collected in Korea. Mycobiology 39(2), 85-91.

Yang FC, Huang HC, Yang MJ. 2003 - The influence of environmental conditions on the mycelial growth of Antrodia cinnamomea in submerged cultures. Enzyme and Microbial Technology 33, 39-402.

Yong JWH, Ge L, Ng YF and Tan SN. 2009 - The chemical composition and biological properties of coconut, (Cocus nucifera L.) water. Molecules 14, 5144-5164. 